\title{
Efectos de la Selección y de la Superovulación en las Pérdidas Gestacionales de Ratonas CF1
}

\author{
Effects of Selection and Superovulation on Gestational Losses in CF1 Mice
}

\author{
"S. F. Bernardi; ${ }^{* *}$ G. Brogliatti \& ${ }^{* * * *}$ M. I. Oyarzabal
}

BERNARDI, S. F.; BROGLIATTI, G. \& OYARZABAL, M. I. Efectos de la selección y de la superovulación en las pérdidas gestacionales de ratonas CF1. Int. J. Morphol., 29(1):204-213, 2011.

RESUMEN: En un par de líneas de ratones seleccionadas para alto $(s$ ') y bajo peso $(s)$, originadas a partir de una población no seleccionada de la cepa $\mathrm{CF} 1(t)$, se modificó la estructura ovárica. El diámetro de los folículos ováricos y el número de folículos y de cuerpos lúteos se incrementaron en las hembras de la línea s', sin expresarse en un mayor tamaño de camada al nacimiento, posiblemente, por un aumento de las pérdidas gestacionales. Se probó si los efectos conjuntos de la selección de peso a largo plazo y de la estimulación ovárica incrementaban las pérdidas gestacionales. Se utilizaron dos grupos de hembras por línea: sin y con estimulación ovárica (5UI de eCG y 5UI de hCG). Las hembras se sacrificaron a las 56-72 hs y a los 7 días postservicio y después de la primera parición. Se observaron los números de cuerpos lúteos (CL), embriones (E) y sitios de implantación (SI) y el tamaño de camada al nacimiento (TC). Se estimaron las pérdidas totales (PT) y las pérdidas de cuerpos lúteos (PCL), de embriones (PE) y de fetos (PF). Los promedios de CL, E, SI y TC variaron en el mismo sentido de la selección practicada y fueron significativamente mayores $(\mathrm{P}<0,05)$ para las hembras estimuladas, a excepción de TC. La línea $s$ ' tuvo un potencial reproductivo superior pero un mayor costo biológico (mayor PT y más tardía) cuando se la comparó con las otras líneas. La estimulación ovárica produjo menores eficiencias reproductivas totales para las tres líneas y pérdidas gestacionales mayores y más tardías, principalmente de SI. Las hembras de la línea no seleccionada $(t)$, no estimuladas, con pesos intermedios, parieron un mayor número de crías, partiendo de un número intermedio de CL, E y SI, con una menor y más temprana mortalidad embrionaria, demostrando ser las más eficientes desde el punto de vista reproductivo y productivo.

PALABRAS CLAVE: Cuerpos lúteos; Embriones; Sitios de implantación; Tamaño de camada; Eficiencia reproductiva.

\section{INTRODUCCIÓN}

Con el propósito de incrementar la producción animal, la práctica de la selección artificial se ha dirigido hacia el aumento del rendimiento de caracteres de interés económico. La respuesta a la selección aumentó los niveles de producción y trajo como consecuencia modificaciones favorables, desde el punto de vista productivo, en otros caracteres no seleccionados (Brien, 1986). Pero también, y muy frecuentemente, ocasionó deterioros de la aptitud por la presencia de problemas reproductivos e inmunológicos (Rauw et al., 1998).

La realización de experimentos, que evalúen estas consecuencias reproductivas de la selección a largo plazo en animales de interés económico, se hace difícil debido a los tiempos y costos que insumen. Una alternativa es utili- zar modelos experimentales en animales de laboratorio con cortos períodos generacionales.

En ratones, la selección para alto peso provocó una pérdida en la fertilidad de las hembras, por disminución de la longitud de la vida reproductiva, aumento de los intervalos entre partos y/o disminución del tamaño de camada a la parición y al destete a lo largo de la vida, que condujeron a una menor producción que las de las hembras pertenecientes a líneas no seleccionadas (Roberts, 1961; Domenichini et al., 1989; Bünger et al., 1992).

En estos casos, la fertilidad podría mejorarse mediante el uso de gonadotrofinas exógenas para incrementar el

\footnotetext{
* Cátedra de Histología I y Embriología Básica. Fac. Cs. Veterinarias, Universidad Nacional de Rosario. Ov. Lagos y Ruta 33. 2170 Casilda. Argentina.

** Actividad Privada. Venado Tuerto. Argentina.

*** Cátedra de Producción de Carne Bovina. Fac. Cs. Veterinarias y Consejo de Investigaciones, Universidad Nacional de Rosario, Argentina.
} 
número de oocitos ovulados. Pero en animales de laboratorio, no seleccionados, se demostró que puede ocasionar efectos adversos sobre el desarrollo embrionario y no incrementar proporcionalmente el tamaño de camada al nacimiento. Miller \& Armstrong (1981) superovularon ratas de 30 días de edad con distintas dosis de gonadotrofina (eCG) y observaron interrupciones en el desarrollo normal de la gestación al compararlas con las hembras control. El uso de eCG incrementó el número de oocitos maduros y de embriones, pero el peso de los fetos implantados fue decreciendo significativamente con el avance de la gestación hasta comprometer su viabilidad para llegar al término de la preñez. Elmazar et al. (1989) encontraron un incremento de la tasa de apareamiento y del número de sitios de implantación, acompañado por un aumento de la mortalidad durante la gestación en ratones superovulados. McKiernan \& Bavister (1998) observaron en hamsters estimulados con gonadotrofinas, que un porcentaje significativamente mayor de embriones permanecían en el estadio de una sola célula, es decir, detenían o demoraban su desarrollo, y que el promedio de embriones con desarrollo normal a las 82 horas posteriores a la fecundación fue significativamente menor al de las hembras control. En el período posterior a la implantación se encontró una reducción significativa del porcentaje de fetos viables en las hembras estimuladas con respecto a las hembras control. Liang et al. (2009) concluyeron que la superestimulación ovárica con gonadotrofinas exógenas en ratones puede producir más oocitos y embriones, sin embargo cuando esta técnica se repite en el tiempo ( 5 ciclos de administración con intervalos de 6 días) puede ocasionar deterioro sobre la calidad de los folículos ováricos y de los embriones, además de reducir el número de oocitos maduros.

En estudios anteriores realizados en la Facultad de Ciencias Veterinarias (U.N.R.) se demostró que la fertilidad se modificó en un par de líneas de ratones de selección divergente para peso a los 49 días de edad, como consecuencia de la selección practicada durante más de 45 generaciones, y por consiguiente disminuyó la producción en gramos. El seguimiento de la vida reproductiva permitió observar que las hembras de la línea no seleccionada, de pesos intermedios, se reproducían regularmente y en forma continuada y daban un número de crías significativamente mayor que el de las hembras de las líneas seleccionadas, alcanzando una mayor eficiencia productiva (Oyarzabal \& Rabasa, 1995). Sin embargo, al analizar la estructura ovárica se comprobó que el desarrollo de los folículos ováricos y la capacidad ovulatoria no explicaban el mayor tamaño de camada de las hembras de esta línea. Las hembras de la línea más pesada fueron las que mostraron diámetros mayores de los folículos ováricos y números mayores de folículos y de cuerpos lúteos, que no se expresaron en un mayor tamaño de camada al nacimiento (Bernardi et al., 2009). Este incre- mento del número de oocitos ovulados atribuible a la selección para alto peso, sin un aumento proporcional del tamaño de camada a la parición, podría deberse a diferencias en las pérdidas embrionarias ocurridas en distintas etapas de la gestación.

Con el propósito de probar los efectos conjuntos de la selección de peso a largo plazo y de la estimulación ovárica sobre las pérdidas gestacionales, se observaron el número de cuerpos lúteos, embriones, sitios de implantación y tamaño de camada a la primera parición en hembras de un par de líneas de ratones de selección divergente de peso a la madurez y de una población testigo no seleccionada, para dos grupos: hembras con y sin estimulación ovárica.

\section{MATERIAL Y MÉTODO}

Líneas seleccionadas de ratones. En 1986, se inició una población testigo de ratones CF1 $(t)$ en la Facultad de Ciencias Veterinarias (Universidad Nacional de Rosario), con $\mathrm{Ne} \leq 20$ y sin selección de los reproductores.

En la generación 2 de $t$ se eligieron al azar los fundadores de un par de líneas de selección divergente para peso corporal a los 49 días de edad: $s$ : línea de selección positiva, $s$ : línea de selección negativa (Oyarzabal \& Rabasa). La selección de peso es fenotípica, se seleccionan como reproductores los animales de pesos más extremos (los más pesados en $s$ ' y los más livianos en $s$ ). Las hembras de la línea $s$ ' pesan en promedio $50 \%$ más que las de $s$. Se practica endocría por limitación del número con tamaño efectivo: $\mathrm{Ne} \leq 8$. La respuesta a la selección de peso en s y en $s^{\prime}$ estuvo acompañada de un deterioro de la fertilidad, no atribuible a la endocría según lo demostrado en trabajos anteriores (Oyarzabal \& Rabasa).

Los animales se mantuvieron en condiciones convencionales con alimento y agua ad libitum, siguiendo las normas de Guide for the Care and Use of Laboratory Animals (Nacional Research Council, 1996). La eutanasia se realizó por dislocación cervical.

Cuerpos lúteos, embriones, sitios de implantación y tamaño de camada. Con el propósito de comparar la capacidad embrionaria de las hembras de las líneas seleccionadas con las de la población testigo y de evaluar los efectos de la estimulación ovárica, se eligieron al azar 72 ratones hembras adultas jóvenes ( 50 a 80 días de edad) por línea, pertenecientes a las generaciones 47 a 50 de $t$ y 44 a 48 del par $s$. Fueron divididas en dos grupos (A y B) y se procedió de la siguiente manera: 
Grupo A (no estimuladas). A 27 ratones se les realizó citología vaginal exfoliativa seriada hasta detectar estro (Feldman \& Nelson, 1996). Toda hembra en estro, recibió servicio en proporción $1 \bullet: 1 \bullet$ durante 24 horas y cuando se comprobó la presencia del tapón vaginal fue asignada a uno de tres subgrupos. Los subgrupos quedaron constituidos por:

A1: 9 hembras sacrificadas entre las 56 y 72 horas posteriores al servicio

A2: 9 hembras sacrificadas a los 7 días posteriores al servicio

A3: 9 hembras que se siguieron hasta la primera parición. A las hembras del subgrupo A1:

a. Se les extirparon los ovarios identificándolos como derecho (D) e izquierdo (I), se les quitó la grasa circundante y se contó el número de cuerpos lúteos (CLD y CLI) con lupa estereoscópica a $4 \mathrm{X}$.

b. Se les extirpó el útero y mediante flushing se obtuvieron los embriones, registrándose el número de embriones del oviducto derecho e izquierdo (ED y EI).

A las hembras del subgrupo A2: se les extirpó el útero y se observó el número de sitios de implantación de cada lado del tracto reproductivo mediante evaluación macroscópica (SID y SII). Se registró el tamaño de camada a la primera parición (TC) de las hembras del subgrupo A3.

Grupo B (con estimulación ovárica). Se sincronizó el estro y se estimuló la ovulación a las restantes 45 ratonas, mediante inyección intraperitoneal de 5UI de eCG (Novormon ${ }^{\circledR}$, Laboratorios Syntex S.A. Argentina) y 48 horas más tarde de 5 UI de hCG (Novormon $®$, Laboratorios Syntex S.A., Argentina). Junto con la administración de hCG, se les dio servicio en proporción $1 \bullet: 1 \bullet$ durante 24 horas. Al comprobarse la presencia del tapón vaginal, las hembras se asignaron al azar a uno de tres subgrupos que quedaron constituidos por:

B1: 15 hembras sacrificadas entre las 56 y 72 horas posteriores al servicio

B2: 15 hembras sacrificadas a los 7 días posteriores al servicio

B3: 15 hembras que se siguieron hasta la primera parición. Para las hembras de estos subgrupos se llevó a cabo el mismo procedimiento que el descripto para las hembras de los subgrupos de A y se registraron las mismas variables.

Variables estudiadas. Número de cuerpos lúteos (CL): suma del número de CL de los ovarios derecho e izquierdo de una hembra.
Número de embriones (E): suma del número de $\mathrm{E}$ de los oviductos derecho e izquierdo de una hembra.

Número de sitios de implantación (SI): suma del número de SI de los cuernos uterinos derecho e izquierdo de una hembra.

Tamaño de camada (TC): número de crías nacidas en la primera parición de una hembra.

Peso (P): peso corporal a los 49 días de edad.

Análisis realizados. La asimetría de las distribuciones del número de cuerpos lúteos, embriones y sitios de implantación condujo a la aplicación de la transformación raíz cuadrada, comúnmente utilizada en este tipo de variables, para la realización de las pruebas de hipótesis (Sokal \& Rohlf, 1979). Se probó la homogeneidad de variancias de las líneas mediante la prueba de Bartlett. La variable peso se transformó a log (peso) en aquellos casos en que se encontraron diferencias significativas entre las variancias.

Se consideró el posible efecto del lado del tracto reproductivo en CL, E y SI y se probó si existían diferencias significativas entre lados para $\sqrt{C L}, \sqrt{E}$ y $\sqrt{S I}$ mediante pruebas $t$-student para datos apareados $(\mathrm{P}<0,05)$, realizadas dentro de los grupos A y B.

El significado de la influencia de la selección de peso y de la estimulación ovárica en las variables CL, E, SI y TC se estimó por análisis de la variancia aplicado a un diseño factorial, a partir del siguiente modelo:

$$
\mathrm{Y}_{\mathrm{ijk}}=\mathrm{m}+\mathrm{a}_{\mathrm{i}}+\mathrm{b}_{\mathrm{j}}+\mathrm{d}_{\mathrm{ij}}+\mathrm{e}_{\mathrm{ijk}}
$$

donde $\mathrm{Y}_{\mathrm{ij \textrm {k }}}$ : valor observado de la variable $\mathrm{Y}$ en la k-ésima hembra perteneciente a la línea i con tratamiento j; m: media general; $a_{i}$ : efecto de la línea $i ; b_{j}$ : efecto del tratamiento $\mathrm{j} ; \mathrm{d}_{\mathrm{ij}}$ : interacción línea por tratamiento y $\mathrm{e}_{\mathrm{ij \textrm {k }}}$ : error aleatorio. Se realizaron pruebas de comparaciones múltiples HSD de Tukey-Kramer $(\mathrm{P}<0,05)$.

Se calcularon los promedios y errores estándar de $\mathrm{P}$, CL, E, SI y TC por línea para las hembras de los grupos A y B.

Mediante los coeficientes de determinación, resultantes de la aplicación de un modelo de regresión lineal de los promedios, por línea y grupo, de cada una de estas variables en $\mathrm{P}$ (variable independiente) se estimaron los porcentajes de variabilidad de CL, E, SI y TC explicados por P.

El efecto de la estimulación ovárica, la eficiencia reproductiva y las pérdidas gestacionales se estimaron a ni- 
vel poblacional a partir de los promedios, debido a que los valores individuales no se pudieron calcular porque CL, E, SI y TC se observaron en grupos diferentes de hembras.

El efecto de la estimulación ovárica relativo al peso corporal para cada etapa gestacional y línea se definió como:

a. Incremento relativo de cuerpos lúteos:

$$
\mathrm{IRC}=\{[(\mathrm{CLB}-\mathrm{CLA}) / \mathrm{CLA}] \times 100\} / \mathrm{P}
$$

b. Incremento relativo de embriones:

$$
\mathrm{IRE}=\{[(\mathrm{EB}-\mathrm{EA}) / \mathrm{EA}] \times 100\} / \mathrm{P}
$$

c. Incremento relativo de sitios de implantación:

$$
\mathrm{IRSI}=\{[(\text { SIB }- \text { SIA }) / \text { SIA }] \times 100\} / \mathrm{P}
$$

d. Incremento relativo del tamaño de camada:

$$
\mathrm{IRTC}=\{[(\mathrm{TCB}-\mathrm{TCA}) / \mathrm{TCA}] \times 100\} / \mathrm{P}
$$

En todos los casos B corresponde al grupo de hembras con estimulación ovárica y $\mathrm{A}$ al de hembras sin tratamiento hormonal.

La eficiencia reproductiva de las líneas a lo largo de la gestación se estimó como cociente entre los promedios de TC y CL, considerando a CL como el límite máximo del tamaño de camada al nacimiento. Para facilitar su interpretación, se estimó la pérdida embrionaria total como contracara de la eficiencia reproductiva y se la particionó en tres, según las etapas de la gestación analizadas. Las estimaciones poblacionales de las pérdidas se definieron como:

Pérdida total: PTOT $=[(\mathrm{CL}-\mathrm{TC}) / \mathrm{CL}] \times 100$

Pérdida de cuerpos lúteos: PCL $=[(\mathrm{CL}-\mathrm{E}) / \mathrm{CL}]$ x 100

Pérdida de embriones: $\mathrm{PE}=[(\mathrm{E}-\mathrm{SI}) / \mathrm{CL}] \mathrm{x} 100$

Pérdida de fetos: $\mathrm{PF}=[(\mathrm{SI}-\mathrm{TC}) / \mathrm{CL}]$ x 100

Todos los análisis estadísticos se realizaron utilizando el programa JMP en su versión 5.0 para Windows (JMP®, SAS Institute, 2003).

\section{RESULTADOS}

El número de cuerpos lúteos, embriones y sitios de implantación del lado derecho del aparato reproductivo, frecuentemente, fue mayor que el del lado izquierdo sin alcanzar significado estadístico en los grupos A y B. Por lo tanto, no se tuvo en cuenta la procedencia de los CL, E y SI y se utilizó la variable: suma de ambos lados por hembra.

Los resultados del análisis factorial mostraron que el número medio de cuerpos lúteos, embriones y sitios de implantación varió en función de la línea y del tratamiento $(\mathrm{P}<0.001)$. El número de crías al nacimiento sólo estuvo influenciado por el efecto de la línea $(\mathrm{P}<0.001)$, no se evidenció interacción significativa para ninguna de las variables estudiadas. En las Tablas I y II se encuentran los promedios, los desvíos estándar y las diferencias entre líneas de P, CL, E, SI y TC para hembras no estimuladas y con estimulación ovárica, respectivamente.

En el período comprendido desde la ovulación hasta el séptimo u octavo día de desarrollo embrionario, las hembras no estimuladas de las líneas seleccionadas alcanzaron valores extremos para los promedios de CL, E y SI en el mismo sentido de la selección de peso; la línea no seleccionada presentó valores intermedios entre ambas. Sin embargo, al momento de la parición, el tamaño de camada de las hembras de esta línea $(t)$ superó al de las seleccionadas ( $s$ y $s^{\prime}$ ) sin diferir significativamente de $s$ ' (Tabla I). Los coeficientes de determinación calculados a partir de los ajustes de un modelo lineal de los promedios por línea de CL, E, SI y TC en P (variable independiente) decrecieron a medida que avanzaron las distintas etapas de la gestación, es decir, el peso corporal explicó una menor proporción de la variabilidad cuando se pasó del análisis de CL, E y SI a TC $\left(\mathrm{R}_{\mathrm{CL}}^{2}=0,98 ; \mathrm{R}_{\mathrm{E}}^{2}=0,99 ; \mathrm{R}_{\mathrm{SI}}^{2}=0,93 ; \mathrm{R}_{\mathrm{TC}}^{2}=0,48\right)$.

Para las hembras estimuladas, los mayores promedios de CL y E correspondieron a la línea más pesada ( $s$ '), les siguieron los de la no seleccionada $(t)$ y por último los de la línea de bajo peso $(s)$. Esta relación con el peso corporal se anuló para el número de sitios de implantación hasta alcanzar la línea $t$ el mayor tamaño de camada promedio. La

Tabla I. Promedios y errores estándar de peso, del número de cuerpos lúteos, embriones y sitios de implantación y del tamaño de camada al nacimiento. Hembras no estimuladas.

\begin{tabular}{lccrrr}
\hline Línea & $\mathbf{P}+\mathbf{E S}$ & $\mathbf{C L}+\mathbf{E S}$ & $\mathbf{E}+\mathbf{E S}$ & $\mathbf{S I}+\mathbf{E S}$ & TC + ES \\
\hline$t$ & $26,12+0,43 \mathrm{~b}$ & $19,11+1,02 \mathrm{a}$ & $13,00+0,94 \mathrm{~b}$ & $11,89+0,51 \mathrm{a}$ & $11,44+0,73 \mathrm{a}$ \\
$\boldsymbol{s}$ & $20,84 \pm 0,57 \mathrm{c}$ & $12,56 \pm 1,09 \mathrm{~b}$ & $9,56 \pm 1,02 \mathrm{~b}$ & $8,67 \pm 0,83 \mathrm{~b}$ & $7,44 \pm 0,82 \mathrm{~b}$ \\
$\boldsymbol{s}^{\prime}$ & $31,11 \pm 1,06 \mathrm{a}$ & $22,67 \pm 1,79 \mathrm{a}$ & $17,50 \pm 1,33 \mathrm{a}$ & $13,00 \pm 1,14 \mathrm{a}$ & $10,22 \pm 1,06 \mathrm{ab}$ \\
\hline
\end{tabular}

P: peso a los 49 días, CL: cuerpos lúteos, E: embriones, SI: sitios de implantación, TC: tamaño de camada al nacimiento. Dentro de columna, letras distintas indican diferencias significativas entre líneas $(\mathrm{P}<0,05)$. 
Tabla II. Promedios y errores estándar de peso, del número de cuerpos lúteos, embriones y sitios de implantación y del tamaño de camada al nacimiento. Hembras con estimulación ovárica.

\begin{tabular}{lccccc}
\hline Línea & $\mathbf{P} \pm \mathbf{E S}$ & $\mathbf{C L} \pm \mathbf{E S}$ & $\mathbf{E} \pm \mathbf{E S}$ & $\mathbf{S I} \pm \mathbf{E S}$ & TC \pm ES \\
\hline $\boldsymbol{t}$ & $25,21 \pm 0,42 \mathrm{~b}$ & $31,07 \pm 1,04 \mathrm{~b}$ & $25,40 \pm 1,37 \mathrm{~b}$ & $17,27 \pm 0,71 \mathrm{a}$ & $11,67 \pm 0,56 \mathrm{a}$ \\
$\boldsymbol{s}$ & $21,73+0,23 \mathrm{c}$ & $23,00+0,88 \mathrm{c}$ & $21,80+1,35 \mathrm{~b}$ & $13,00+0,75 \mathrm{~b}$ & $8,33+0,72 \mathrm{~b}$ \\
$\boldsymbol{s}^{\prime}$ & $31,86+0,52 \mathrm{a}$ & $36,53+1,16 \mathrm{a}$ & $32,73+1,10 \mathrm{a}$ & $16,87+1,11 \mathrm{ab}$ & $9,73+0,73 \mathrm{ab}$ \\
\hline
\end{tabular}

P: peso a los 49 días, CL: cuerpos lúteos, E: embriones, SI: sitios de implantación, TC: tamaño de camada al nacimiento. Dentro de columna, letras distintas indican diferencias significativas entre líneas $(\mathrm{P}<0,05)$.

línea $s$ mantuvo para todas las variables los valores más bajos (Tabla II). La disminución de la dependencia durante el transcurso de la gestación, desde la ovulación hasta la parición, se observó en los coeficientes de determinación que tuvieron valores prácticamente iguales a uno para CL y E, no así, para SI y muy bajo para TC, demostrando que el peso corporal de la madre poco puede explicar de la variabilidad del tamaño de camada en las hembras con estimulación ovárica $\left(\mathrm{R}_{\mathrm{CL}}^{2}=0,92 ; \mathrm{R}_{\mathrm{E}}^{2}=1,00 ; \mathrm{R}_{\mathrm{SI}}^{2}=0,50\right.$; $\left.\mathrm{R}_{\mathrm{TC}}^{2}=0,06\right)$.

Los promedios de CL, E y SI fueron significativamente mayores para las hembras estimuladas, no así para TC. El tratamiento con gonadotrofinas incrementó el número medio de embriones (IRE) en mayor proporción que el resto de las variables para las tres líneas. La línea $s$ fue la que mejor respondió al tratamiento, partió de un menor potencial reproductivo y alcanzó mayores IRCL, IRE, IRSI e IRTC (Tabla III).
Tabla III. Incremento relativo del número de cuerpos lúteos, embriones y sitios de implantación y tamaño de camada en tres líneas de ratones.

\begin{tabular}{lcccc}
\hline Lín & IRCL & IRE & IRSI & IRTC \\
\hline $\boldsymbol{t}$ & 2,44 & 3,72 & 1,76 & 0,08 \\
$\boldsymbol{s}$ & 3,91 & 6,02 & 2,35 & 0,56 \\
$\boldsymbol{s}^{\prime}$ & 1,94 & 2,85 & 0,94 & $-0,15$ \\
\hline
\end{tabular}

IRCL, IRE, IRSI e IRTC: incremento relativo del número de cuerpos lúteos, embriones y sitios de implantación y tamaño de camada, respectivamente.

En el grupo A, al relacionar el tamaño de camada con el número de cuerpos lúteos se observó que las líneas $t$ y $s$ tuvieron una eficiencia reproductiva similar $(\mathrm{ER} t=0,60 ; \mathrm{ER} s=0,59)$ y superior a la de la línea $s^{\prime}\left(\mathrm{ER} s^{\prime}=\right.$ $0,45)$. Esto fue así porque durante el proceso de gestación, la línea seleccionada para alto peso $(s ')$ presentó la mayor pérdida total $(\sim 55 \%)$. Pero si se analizan las pérdidas embrionarias por etapa, se puede observar que las hembras

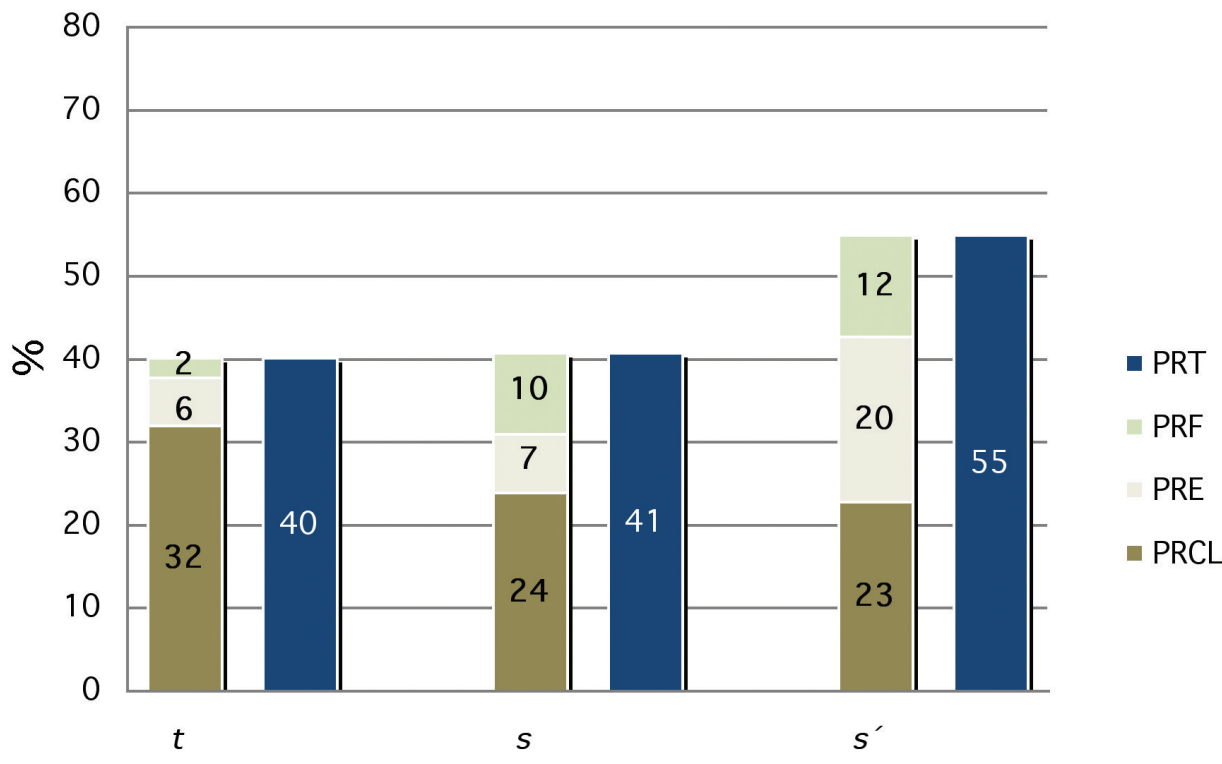

Fig. 1. Pérdida total y por etapas de gestación en tres líneas de ratones. 


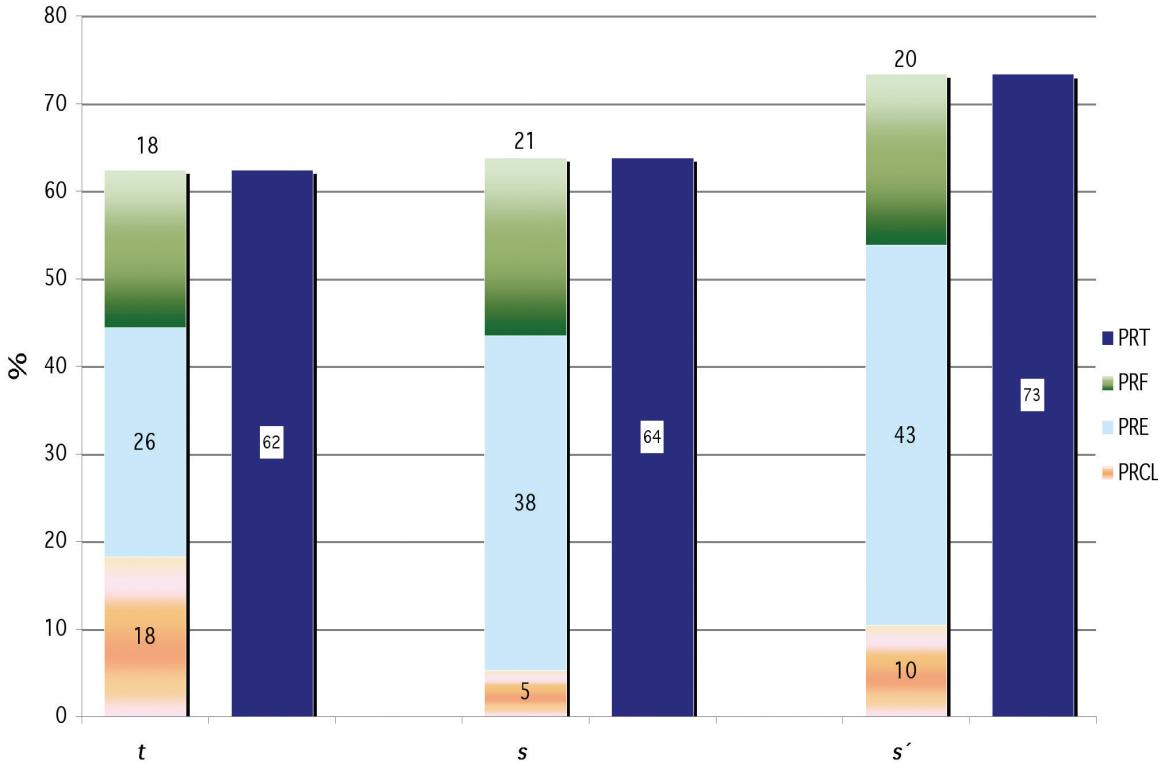

Figura 2. Pérdida total y por etapas de gestación en tres líneas de ratones. Hembras con estimulación ovárica. de las líneas $t$ y $s$ tuvieron pérdidas mayores en la primera etapa, y menores en la segunda y tercera. Mientras que $s$, mostró pérdidas similares en la primera y segunda etapa, y fue la línea con mayores pérdidas en la segunda y tercera etapas (Fig. 1).

Para las hembras estimuladas, la relación entre el tamaño de camada y el número de cuerpos lúteos demostró que las hembras de las líneas $t$ y $s$ tuvieron mayor capacidad para convertir los oocitos ovulados en crías paridas (ER $t=$ 0,37, ERs $\left.=0,36, E R s^{\prime}=0,27\right)$ y las hembras $s$ 'presentaron el mayor porcentaje de pérdidas gestacionales (Fig. 2). Al analizar las pérdidas por etapa, las líneas seleccionadas tuvieron pérdidas menores que la testigo durante el primer período evaluado (PRCL), mayores en la segunda etapa (PRE) y similares en la tercera (PRF) (Fig. 2).

La estimulación ovárica produjo menores eficiencias reproductivas totales para las tres líneas y pérdidas gestacionales mayores y más tardías, principalmente de sitios de implantación (Figs. 1 y 2).

\section{DISCUSIÓN}

Los caracteres de fertilidad evaluados y la sobrevida durante la gestación se modificaron en las hembras de las dos líneas seleccionadas de ratones, durante las casi 50 generaciones de selección divergente de peso corporal, como se demostró al compararlas con las de la línea no seleccionada de la cual provienen.
Los números de cuerpos lúteos, embriones y sitios de implantación variaron en relación directa con la selección de peso realizada, como fuera demostrado por otros autores en distintas especies políticas: en ratones (Lubritz et al., 1991), en conejos (Argente et al., 1999), en cerdos (RuizFlores \& Johnson, 2001).

Sin embargo, esta relación en función del peso corporal no se mantuvo hasta la parición y la línea más pesada no presentó el mayor tamaño de camada a pesar de haber tenido una mayor tasa de ovulación. Esto último, coincide con lo expresado por Bünger et al. quienes encontraron que el tamaño de camada se redujo en ratones seleccionados para alto peso corporal a los 42 días de edad.

El análisis de las pérdidas en distintos momentos de la gestación permitió explicar el hecho de que a partir de un mayor número de embriones no se produjera un mayor número de crías paridas. El mayor porcentaje de mortalidad embrionaria total de la línea positiva $\left(s^{\prime}\right)$ acuerda con lo publicado por Land \& Falconer (1969), quienes al trabajar con ratones seleccionados por peso a las 6 semanas de edad demostraron que existe una correlación positiva entre peso corporal, tasa de ovulación y mortalidad embrionaria. En otras líneas de ratones seleccionados por tasa de crecimiento se observó que las hembras de las líneas positivas sufrieron también una mayor pérdida embrionaria al compararlas con las de la línea control (Bradford, 1971; Dilts et al., 1991).

Las pérdidas por etapa evidenciaron estrategias diferentes de las líneas. Las hembras de la línea no seleccionada tuvieron su mayor pérdida tempranamente (PRCL), siendo 
muy baja la mortalidad de embriones y de fetos (PRE y PRF). En cambio, en las líneas seleccionadas, las hembras redujeron el porcentaje de pérdida durante la primera etapa incrementado la mortalidad postimplantacional, principalmente $s^{\prime}$, aunque sigue siendo mayor la pérdida preimplantacional.

En otros experimentos de selección por tasa de ovulación, tampoco se mantuvo una relación positiva entre tasa de ovulación y tamaño de camada y aumentaron las pérdidas gestacionales (Bradford, 1969; Land \& Falconer; Ribeiro et al., 1997).

En ambos casos, ya sea como consecuencia de la selección de peso o por selección directa de la tasa de ovulación, sería imposible lograr un mayor tamaño de camada si el incremento de la tasa de ovulación no estuviera acompañado por una mayor capacidad uterina como lo demuestran los resultados obtenidos por otros autores. Blasco et al. (2005), en un par de líneas de conejos de selección divergente por capacidad uterina encontraron una respuesta correlacionada de la tasa de ovulación con el tamaño de camada. Ibañez et al. (2006), en una línea de conejos seleccionada por tasa de ovulación, previamente seleccionada por capacidad uterina, encontraron una respuesta correlacionada genéticamente con el tamaño de camada y una respuesta correlacionada desfavorable con la sobrevida embrionaria prenatal. En cerdos, RuizFlores \& Johnson demostraron que cuando la tasa de ovulación es alta, la selección por tamaño de camada incrementa la capacidad uterina y ésto hace que se incremente el tamaño de camada a la parición. Holt (2004) observó pérdidas gestacionales tardías (entre los días 17 y 20) en ratones seleccionados por tamaño de camada durante 110 generaciones. Spitschak et al. (2007) comprobaron en ratones seleccionados para alta fertilidad una mayor proporción de pérdidas postimplantacional y la explicaron por limitación de la capacidad uterina. En conejos, en un par de líneas de selección divergente para capacidad uterina no hubo diferencias significativas entre las líneas para la tasa de ovulación y de fertilización, sin embargo, sí las hubo para el estadio de desarrollo de los embriones recolectados a las 72 horas de gestación. Además, la sobrevida fetal tanto temprana (entre 7 y 17 días de gestación) como tardía (entre 17 y 28 días de gestación) fue mayor cuando los embriones donados por hembras con alta y baja capacidad uterina fueron depositados en oviductos de hembras con alta capacidad uterina, evidenciándose que la sobrevida fetal depende del genotipo materno, el genotipo embrionario solo afecta la sobrevida cuando este es transferido a un ambiente materno favorable (Mocé et al., 2004; Blasco et al.; Santacreu et al., 2005; Peiró et al., 2007).

En las tres líneas de ratones, la administración de gonadotrofinas para estimular la función ovárica incrementó las pérdidas totales ocurridas a lo largo de la gestación. Si la mortalidad se analiza por etapas y se compara con lo ocurrido en las hembras sin estimular, se desprende que las pérdidas relativas de cuerpos lúteos disminuyeron prácticamente a la mitad, pero a la vez aumentaron las pérdidas relativas de embriones y de fetos. De lo anterior se deduce que un efecto negativo importante de la superovulación fue el incremento de las pérdidas gestacionales totales. Mehaisen et al. (2005) al utilizar gonadotrofinas en dos líneas de conejos seleccionados por tamaño de camada y por tasa de crecimiento, observaron que si bien se incrementó la tasa de ovulación no se evidenciaron diferencias significativas en el número de embriones desarrollados in vivo y postvitrificación.

La incidencia de una mortalidad embrionaria mayor debida al uso de gonadotrofinas para estimular la función ovárica también fue demostrada en animales sobre los que no se practicó selección artificial. Van de Auwera \& D'Hooghe (2001) demostraron que la superovulación en ratones causa un deterioro en el desarrollo embrionario in vitro e in vivo, un incremento de blastocistos con formación anormal, un pronunciado retardo en el crecimiento fetal y una mayor mortalidad al momento de la implantación. Los autores sostienen que tales efectos pueden explicarse por un deterioro en la calidad de los oocitos, por una influencia negativa del medio ambiente uterino sobre el desarrollo embrionario y por una baja receptividad endometrial. Ertzeid \& Storeng (2001) observaron que la tasa de implantación al día 5 de gestación en ratones fue mayor para embriones obtenidos de hembras superovuladas y transferidos a úteros de hembras control que los recibidos en úteros de hembras superovuladas. Por otro lado, la menor tasa de implantación se dio en embriones de donadoras control transferidos a receptoras estimuladas, poniéndose de manifiesto que el medio uterino estimulado tiene influencias negativas sobre la capacidad de implantación incrementado la mortalidad. Sibug et al. (2002) relacionaron las desventajas observadas durante el período de implantación embrionaria con la reducción de la expresión de un factor de crecimiento del endotelio vascular $\left(\mathrm{VEGF}_{120}\right)$ considerado el más potente como estimulador de la angiogénesis durante ese período. Esto conlleva una reducción en el tamaño de los sitios de implantación (día 5 y 6) y prolonga el período gestacional en ratones. La expresión del factor mencionado está asociada al proceso de implantación, en la aposición del blastocisto con el epitelio endometrial, estadio inicial de la implantación que coincide con un incremento de la permeabilidad vascular y con un amplio crecimiento devasos sanguíneos en el endometrio. Liang et al. demostraron que la estimulación ovárica en ratones permite producir más oocitos y embriones, pero la estimulación reiterada genera un efecto negativo sobre la calidad folicular y embrionaria peligrando la sobrevida de ambas estructuras. Además se ha demostrado que la administración de gonadotrofinas afecta 
significativamente la morfología del endometrio durante la implantación afectando consecuentemente su capacidad de receptividad del embrión (Dursun et al., 2004; Salehnia et al., 2006).

En cerdos, el control de la ovulación por gonadotrofinas reveló una marcada diversidad de estadios de desarrollo (de 1 a 4 células) en los embriones recolectados 24 horas posteriores al apareamiento, esta disparidad incidió directamente sobre el momento de implantación de los mismos y la efectividad de dicho proceso (Nissen et al., 2000; Ford et al., 2002) estudiaron la capacidad uterina en cerdos tomando dos efectos: el medioambiente uterino y el genotipo del feto. Observaron que el número de embriones puede incrementarse experimentalmente (a los 30 días) usando superovulación y superinducción; sin embargo, la lechigada de estas hembras tuvieron un número similar de cerdos al compararlas con las hembras control. Lo cual demostró que entre el día 30 y la parición hubo un período de pérdidas fetales significativo. Los autores concluyeron que para lograr un buen tamaño de camada el principal factor es controlar la mortalidad embrionaria que pueda acontecer durante la gestación, más importante aún que el número de embriones viables disponibles en el oviducto.

Los resultados obtenidos corresponden a la administración de una dosis fija de 5 U.I. por hembra, no habiendo variado la dosis en función del peso. La opción elegida fue reconocida como óptima y utilizada por diversos investigadores (Elmazar et al.; Van de Auwera \& D'Hooghe; Ertzeid \& Storeng; Sibug et al., 2002). En este sentido, Fowler \& Edwards (1960) al probar diferentes dosis de gonadotrofinas, desde 0,25 a 6 U.I., en ratones con selección divergente de peso, demostraron que el número de óvulos producidos con cada dosis fue independiente del peso. Por otra parte, Byers et al. et al. (2005) al evaluar la eficiencia de la estimulación ovárica en veintiocho cepas de ratones, demostraron que la respuesta a la superovulación depende de la propia cepa (genotipo).

En síntesis, la eficiencia reproductiva de las hembras superovuladas de las tres líneas fue menor que la de las hembras sin estimulación ovárica, y la línea seleccionada para alto peso, en ambos grupos, fue la de menor eficiencia reproductiva. En estas líneas, los efectos conjuntos de la selección de peso y de la estimulación ovárica que incrementaron la tasa de ovulación provocaron un incremento de las pérdidas gestacionales que podría deberse a limitaciones de la capacidad uterina. Las hembras de la línea no seleccionada $(t)$, sin estimulación ovárica, con pesos intermedios, parieron un mayor número de crías, partiendo de un número intermedio de cuerpos lúteos, de embriones y de sitios de implantación, con una menor y más temprana mortalidad embrionaria, demostrando ser las más eficientes desde el punto de vista reproductivo y productivo, como fuera citado en la Introducción. Esta relación reproducción-producción se vuelve especialmente importante, en algunas especies (cerdos y conejos), en las que una característica reproductiva puede ser a la vez una característica productiva.

\section{CONCLUSIONES}

La selección de peso corporal continua y la estimulación ovárica modificaron la eficiencia reproductiva y el control de la mortalidad embrionaria de las hembras de las dos líneas seleccionadas y estimuladas, fundamentalmente la de alto peso, siendo las hembras de peso corporal intermedio, no estimuladas, las más eficientes reproductivamente y con bajos costos biológicos tardíos atribuibles a pérdidas gestacionales.

BERNARDI, S. F.; BROGLIATTI, G. \& OYARZABAL, M. I. Effects of selection and superovulation on gestational losses in CF1 mice. Int. J. Morphol., 29(1):204-213, 2011.

SUMMARY: The ovarian structure was modified as a consequence of weight selection in a pair of mouse lines selected for high (s') and low weight (s). Lines were founded from an unselected population of CF1 strain (t). The follicle diameter and the number of the ovarian follicles and the corpora lutea were higher in s' females, but they did not reach a larger litter size at birth, may be, by an increase in the gestational losses. In these lines, the co-effects of long-term weight selection and ovarian stimulation were tested to evaluate if they increased gestational losses. Two groups of females per line were employed: without and with ovarian stimulation (5UI of eCG and 5UI of hCG). Females were slaughtered at 56-72hs and at 7 days post-breeding and after first parturition. The number of corpora lutea (CL), embryos (E) and implantation sites (SI), and litter size at birth (TC) were observed. Total losses (PT) and corpora lutea (PCL), embryo (PE) and fetus (PF) losses were estimated. Mean CL, $\mathrm{E}, \mathrm{SI}$ and TC varied in the same direction of the selection made and they were significantly higher $(\mathrm{P}<0.05)$ in stimulated females, though not for TC. Line s' had a higher reproductive potential but a greater biological cost (higher and later gestational mortality) when compared with the other lines. Ovarian stimulation produced lower total reproductive efficiencies for the three lines and higher and later gestational losses, mainly for implantation sites. Females from unselected line $(\mathrm{t})$, without ovarian stimulation, with intermediate weights, bore larger litters, starting from an intermediate number of CL, E and SI, with a lower and earlier embryo mortality, showing to be the most efficient from a reproductive and productive point of view.

KEY WORDS: Corpora lutea; Embryos; Implantation sites; Litter size; Reproductive efficiency 
BERNARDI, S. F.; BROGLIATTI, G. \& OYARZABAL, M. I. Efectos de la selección y de la superovulación en las pérdidas gestacionales de ratonas CF1 Int. J. Morphol., 29(I):204-213, 2011.

\section{REFERENCIAS BIBLIOGRÁFICAS}

Argente, M. J.; Santacreu, M. A.; Climent, A.; Bolet, G. \& Blasco, A. Divergent Selection for Uterine Capacity in Rabbits. J. Anim. Sci., 75:2350-4, 1999.

Bernardi, S.; Brogliatti, G. \& Oyarzabal, M. I. Ovarian structure in mice lines selected for weight. Anat. Histol. Embryol., 38:200-3, 2009.

Blasco, A.; Ortega, J. A.; Climent, A. \& Santacreu, M. A. Divergent selection for uterine capacity in rabbits. I. Genetic parameters and response to selection. J. Anim. Sci., 83:2297-302, 2005.

Bradford, G. E. Genetic control of ovulation rate and embryo survival in mice. I. Response to selection. Genetics, 6:905-21, 1969.

Bradford, G. E. Growth and reproduction in mice selected for rapid body weight gain. Genetics, 69:499-512, 1971.

Brien, F. D. A Review of the Genetic and Physiological Relationships Between Growth and Reproduction in Mammals. Anim. Breed., 54:975-97, 1986.

Bünger, L.; Renne, U. \& Dietl, G. Selection for body weight at 42 days in laboratory mice with and without litter size standardization. Direct response and correlated effects on litter size. Arch. Tierz. Dummerstorf, 35:305-19, 1992.

Byers, S. L.; Payson, S. J. \& Taft, R. A. Performance of ten inbred mouse strains following assisted reproductive techonologies (ARTs). Theriogenology, 65:1716-26, 2005.

Dilts, R. B.; Famula, T. R. \& Bradford, G. E. Ovulation rate and pre and postimplanttion survival in mice with a major gene for rapid postweaning gain. J. Anim. Sci., 69:35906, 1991.

Domenichini, M.; Picardi, L. \& Rabasa, S. L. Depresión de la aptitud por selección en ratones con endocría. Mendeliana, 9:57-66, 1989.

Dursun, A.; Sendag, F.; Terek, M.; Yilmaz, H.; Oztekin, K.; Baka, M. \& Tanyalcin, T. Morphometric changes in the endometrium and serum leptin levels during the implantation period of the embryo in the rat in response to exogenous ovarian stimulation. Fertil. Steril., 82:11216, 2004.
Elmazar, M. M.; Vogel, R. \& Spielmann, H. Maternal factors influencing development of embryos from mice superovulated with gonadotropins. Reprod. Toxicol., $3: 135-8,1989$.

Ertzeid, G. \& Stoteng, R. The impact of ovarían stimulation on implantation and fetal development in mice. Human Reprod., 16:221-5, 2001.

Feldman, E. C. \& Nelson, R. W. Endocrinología y reproducción canina y felina. Buenos Aires, Intermédica, 1996.

Fowler, R. E. \& Edwards, R. G. The fertility of mice selected for large or small body size. Genet. Res., 1:393-407, 1960.

Ford, S. P.; Vonnahme, K. A. \& Wilson, M. E. Uterine capacity in the pig reflects a combination of uterine environment and conceptus genotype effects. J. Anim. Sci., 80:E66-E73, 2002.

Holt, M.; Vangen, O. \& Farstad, W. Components of litter size in mice after 110 generations of selection. Reproduction, 127:587-92, 2004.

Ibañez, N.; Santacreu, M. A.; Martinez, M.; Climent, A. \& Blasco, A. Selection for ovulation rate in rabbits. Livestock Science, 101:126-33, 2006.

Land, R. B. \& Falconer, D. S. Genetic studies of ovulation rate in the mouse. Genet. Res., 13:25-46, 1969.

Liang, L.; Xu, B. \& Zhu, G. Effect of repeated gonadotropin stimulation on ovarian reserves and proliferation of ovarian surface epithelium in mice. Frontiers of Medicine in China, 3:220-6, 2009.

Lubritz, D. C.; Eisen, E. J. \& Robison O. W. Effect of selection for litter size and body weight on hormone induced ovulation rate in mice. J. Anim. Sci., 69:4299305, 1991 .

McKiernan, S. H. \& Bavister, B. D. Gonadotrophin stimulation of donor females decreases post-implantation viability of cultured one-cell hamster embryos. Hum. Reprod., 13:724-9, 1998.

Mehaisen, G. M.; Vicente, J. S.; Lavara, R. \& Viudes de Castro, M. P. Effect of eCG dose and ovulation induction 
treatments on embryo recovery and in vitro development post-vitrification in two selected lines of rabbit does. Anim. Reprod. Sci., 90:175-84, 2005.

Miller, B. G. \& Armstrong D. T. Superovulatory doses of pregnant mare serum gonadotropin cause delayed implantation and infertility in immature rats. Biol. Reprod., 25:253-60, 1981.

Mocé, M. L.; Santacreu, M. A.; Climent, A. \& Blasco, A. The effect of divergent selection for uterine capacity on prenatal survival in rabbits: Maternal and embryonic genetic effects. J. Anim. Sci., 82:68-73, 2004.

National Research Council. Guide for the Care and Use of Laboratory Animals. Institute of Laboratory Animal Research, Commission on Life Sciences. ISBN: 0-30958869-3, 1996. p.140. Avalaible in: http://www.nap.edu/ catalog/5140.html.

Nissen, A. K.; Schmidt, M.; Hyttel, P. \& Greve, T. Ovulation and embryonic developmental rate following hCG-stimulation in sows. Acta Vet. Scand., 41:321-8, 2000 .

Oyarzabal, M. I. \& Rabasa, S. L. Selección divergente de peso en ratones con alta endocría seguida de 90 generaciones de cría libre. Mendeliana, 10:119-32, 1995.

Peiró, R.; Santacreu, M. A.; Climent, A. \& Blasco, A. Early embryonic survival and embryo development in two lines of rabbits divergently selected for uterine capacity. J. Anim. Sci., 85:1634-9, 2007.

Rauw, W. M.; Kanis, E.; Noordhuizen-Stassen, E. N. \& Grommers, F. J. Undesirable side effects of selection for high production efficiency in farm animals: a review. Livest. Prod. Sci., 56:15-33, 1998.

Ribeiro, E. L.; Nielsen, M. K.; Leymaster, K. A. \& Bennett, G. L. A Simulation Model Including Ovulation Rate, Potential Embryonic Viability, and Uterine Capacity to Explain Litter Size in Mice: II. Responses to Alternative Criteria of Selection. J. Anim. Sci., 75:652-6, 1997.

Roberts, R. C. The lifetime growth and reproduction of selected strains of mice. Heredity, 16:369-81, 1961.

Ruiz-Flores, A. \& Johnson, R. K. Direct and correlated responses to two-stage selection for ovulation rate and number of fully formed pigs at birth in swine. J. Anim. Sci., 79:2286-97, 2001.
Salehnia, M.; Arianmanesh, M. \& Beigi, M. The impact of ovarian stimulation on mouse endometrium: a morphometrical study. Iranian J. Reprod. Med., 4:7-11, 2006.

Santacreu, M. A.; Mocé, M. L.; Climent, A. \& Blasco, A. Divergent selection for uterine capacity in rabbits. II. Correlated response in litter size and its components estimated with a cryopreserved control population. $J$. Anim. Sci., 83:2303-7, 2005.

Sibug, R. M.; Helmerhorst, F. M.; Tijssen, A. M. I.; Kloet, E. R. \& Koning, J. Gonadotrophin stimulation reduces VEGF120 expression in the mouse uterus during the peri-implantation period. Human Reprod., 17:1643-8, 2002.

Sokal, R. R. \& Rohlf, F. J. Biometría. Madrid, H. Blume Ed., 1979.

Spitschack, M.; Langhammer, M.; Schneider, F.; Renne, U. \& Vanselow, J. Two high-fertility mouse lines show differences in component fertility traits after long-term selection. Reprod. Fertil. Dev., 19:815-21, 2007.

Van der Auwera, I. \& D'Hooghe, T. Superovulation of female mice delays embryonic and fetal developement. Human Reprod., 16:1237-41, 2001.

Correspondence to:

Bernardi, S. F.

Cátedra de Histología I y Embriología Básica

Facultad de Ciencias Veterinarias

Universidad Nacional de Rosario

Ov. Lagos y Ruta 33. 2170 Casilda

ARGENTINA

Email: sbernard@unr.edu.ar

Recibido : 31-08-2010

Aceptado: 30-11-2010 